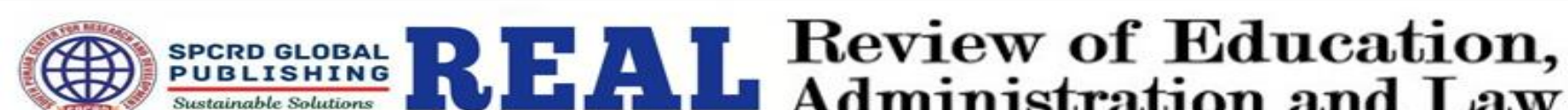 \\ Journal homepage: http://real.spcrd.org ISSN (Print): 2708-1788 ISSN (Online): 2708-3667
}

\section{Agriculture Biomass and Indoor Air Pollution as Risk Factors for Women Health}

\author{
${ }^{a}$ Syed Waqas Shabbir, ${ }^{b}$ Nazia Malik \\ ${ }^{a}$ PhD Scholar, Government College University, Faisalabad, Pakistan \\ Email: Syedwaqasshabbir1149@gmail.com \\ ${ }^{\mathrm{b}}$ Assistant Professor, Government College University, Faisalabad, Pakistan \\ Email: naziamalik@gcuf.edu.pk
}

\begin{tabular}{ll}
\hline ARTICLE DETAILS & ABSTRACT \\
\hline History: & This research looks at the effects of biomass and air pollution on \\
Accepted o6 April 2021 & women's health. Respondents were surveyed using a multi-stage \\
Available Online June 2021 & questionnaire. Data was collected purposively. A self-designed survey \\
& (72 items) was used to collect data Results show that a strong \\
Keywords: & correlation was established between age and nonrespiratory diseases. \\
Indoor Air Pollution, Risk Factor, & The findings reveal that a positive relationship was found between age, \\
Women Health, Respiratory & respiratory disease, and non-respiratory diseases. It indicates that age \\
Disease & predicts health-related among women. The study's findings show that \\
& the use of Agriculture Biomass (UAB), Indoor Air Pollution (IAP), \\
JEL Classification: & Frequency of Usage (FU), Kitchen Type (KT), Kitchen Ventilation System \\
Q53, D81, H51 & (KVS), and Time Spent in Kitchen (TSK) have a significant impact on \\
& women's respiratory diseases (WRD), whereas the type of stove (ST) \\
and exposure to smoke (ES) have no significant impact on women's & health. Collectively, these variables predict up to 20\% of respiratory \\
DoI: 10.47067/real.v4i2.141 & Asthmases (Upper and lower respiratory infection, Cough, Lung cancer, \\
& predict 36.9\% of non-respiratory diseases (Diminished vision, Eye \\
irritation, Watering of eyes, Running of the nose, Cough/without & phlegm, Hypertension, Stroke, Skin irritation/skin burn and \\
Miscarriages, Stillbirth and Low birth weight) in women.
\end{tabular}

Corresponding author's email address: Syedwaqasshabbir1149@gmail.com

\section{Introduction}

In Pakistan, the primary source of energy production is still the conservative and traditional methods instead of using the modern ones. One of the major reasons there are energy problems in Pakistan is the expensive fossil fuels because the local and household industries still rely on natural gas and kiln oil to meet their energy needs (Ali et al., 2016). Presently, the major fuel sources in Pakistan are hydroelectric power, oil, nuclear, natural gas, and coal (World Energy Council, 2016). Since Pakistan has been facing horrible energy problems, it has imported fossil fuels for its industrial and domestic use (Arshad et al., 2016), but energy needs remain. Because of this, the government is now considering using other sources for energy production, like solar energy, biomass and wind energy, etc. 
Biomass from different resources could prove to be a major source of energy since it is easily available and is not costly. Pakistan is an agricultural country with agriculture making up over $60 \%$ of the economy and nearly $62 \%$ of the village population using biomass to meet their energy needs.

People living in rural areas don't readily get access to fossil fuels, and thus, they rely on other resources like animal dung, crop remains, and wood to fulfill their energy needs (Uddin et al. 2016. Energy from renewable resources, especially biomass, can play a significant role in meeting Pakistan's energy requirements (Ahmed et al., 2016).

Biomass is a new form of renewable energy source, which can be used to deal with the future energy requirements of many developing countries. These developing countries also include Pakistan, which needs serious attention towards utilizing this resource to meet its energy demands. The goal of this article was to shed light on the effectiveness and efficiency of biomass as a reliable and renewable source of energy to meet future demands, as well as to discuss the areas that still require much development and policy regulations for such a resource to be utilized to its full potential.Seeing the benefits of bioenergy, the government has taken some steps to utilize it. However, these utilizations further need to speed up, and greater emphasis must be put on bioenergy usage for the country's energy requirements (Jamali et al., 2017). It is also essential to figure out better techniques for the proper conversion of bio resources and flexible fuels like char, vapors, oils, and pyrolysis and synthesis gas can be further used to synthesis methane, ethane, dimethyl ether (DME) hydrogen, etc. This fuel can be used either as a fuel for generating energy or creating a wide range of chemicals to be used in industries (Ahmed et al., 2016).

Biomass fuel creates a large amount of pollution, especially when combusted incompletely (e.g., $\mathrm{CO}, \mathrm{SO} 2$, particulate matter, etc.). Such fuels can have drastic impacts on human health by causing many diseases (like asthma, cancer, respiratory tract infections, cataract, chronic obstructive lung disease, tuberculosis, cardiovascular diseases). It also damages the neonatal outcome (infant mortality, low birth weight, preterm delivery, etc.)

Since prehistoric times, biomass has been the primary source of energy. Biomass energy consumption dates back to antiquity. In many developed countries, even modern day biomass has served as the main household fuel source (Kumar et al., 2015). A study has been conducted to discover more effective methods of using biomass, and several experimental trials have been conducted without harming the ecosystem in order to maximize the benefit from this energy source.The use of biomass oil is of prime significance in developing countries with energy deficits due to less investment in capital, low cost of development of energy, year-round accessibility of their services and the stipulation of huge opportunities for jobs. This is why, in comparison with other green energies, bio-mass energy has the maximum weight priority of 0.318 (Amer and Daim, 2011).

"Biomass" refers to as "naturally occurring flammable material." Biomass is composed of crop residues, animal dung, wood, and grasses (Goldemberg, 2000). At the household use level, agricultural residues are essential for energy (Scott et al., 2014). The least used form of biomass is dung (Goldemberg, 2000). The alternative form used is fuel-wood that is comparatively easy to obtain.

Including Pakistan, 11-under developed countries suffer from 1.2 million deaths a year because of bio-fuel exposure. With more than half (55.6\%) of the country's population, Punjab is Pakistan's largest province. Nearly 68\% of Punjab people are from rural areas (Government of Punjab, 2013). The main reason for the usage of biomass fuel in households in this region is poverty. It is extremely dangerous 
for public health to be heavily reliant on coal and bio-fuels as primary energy sources (Ezzati \& Kammen, 2002).

Women are not considered equal economic opportunities in Punjab (Gull \& Pulla, 2014). Women are usually responsible for the household cooking and they practice this three to four times daily. They are also responsible for collecting agricultural waste and animal dung for house use. Culturally, women's education has been of lower priority, which has led to unawareness of the ill effects of their lifestyles on the masses of women (Dasgupta et al., 2006). There is a strong link between an individual's preferred energy source and their poverty and gender.There is also a lack of international efforts to improve women's energy rights (Danielsen, 2012).

Many PM, as well as hydrocarbons, oxygenated organics, and chlorinated organics, are caused by open fires with bio-fuel in rural areas (Naeher et al., 2007). The categorization of particulate matter is done according to size. This gives ten $\mu \mathrm{m}$ or smaller particles the name PM10. WHO has set a 24-hour average PM level to measure the air quality? According to this set, $50 \mu \mathrm{g} / \mathrm{m} 3$ for PM10 while $25 \mu \mathrm{g} / \mathrm{m} 3$ for PM2.5 (WHO, 2006). However, this standard is much crossed by many developing countries which have more than $2000 \mu \mathrm{g} / \mathrm{m} 3$ of PM10 (Zhang and Morawska, 2002). In a rural village in Punjab which was studied for the amount of indoor air pollution and particulate matter, PM levels ranged from 4000 to $8500 \mu \mathrm{g} / \mathrm{m} 3$ (Colbeck, 2010).

The world health organization reports 4.3 million deaths each year due to bio-fuels creating indoor air pollution (WHO, 2018). A significant relationship exists between the fuel type and the effects on health and diseases (Akhtar et al., 2007). Female deaths in poor and developing countries because of these fuels and this pollution rank as the 5th most significant cause of death (Mathers et al., 2006). Unfortunately, one of the worst countries in this regard is Pakistan (WHO, 2018). Women in Punjab are reported to have asthma, coughs, shortness of breath, and other respiratory issues that worsen as time passes (Jamali et al., 2017).

The world's biggest environmental issues are indoor air emissions (IAP). It is mainly caused by solid cooking fuels that contain biomass (for example, wood, plant residues, animal dung and carbon). For any reason leading to indoor air pollution and adding to environmental air pollution, I AP refers to the infection of solid combustion air within the home. In 2016, almost 2.6 million people died of global IAP diseases prematurely, according to the Institute for Health Metrics and Evaluation (IHME).

In Southeast Asia, the IAP is the world's leading cause of life-years for people with disabilities (DALYs) and the third leading reason for DALYs. According to the global Burden of Disease report, it is regarded as a silent assassin, resulting in 4.3 million deaths worldwide, representing $7.7 \%$ of total deaths. As a result of the indoor air contamination and the Western Pacifique zone, the South-East Asian region adds to the peak mortality. Pneumonia, stroke, ischemic heart disease (IHD), chronic obstructive lung disease (COPD) and poor obstetrics are primary health problems contributing to global IAP mortality. The existing literature shows that data on access to renewable cooking fuels can be used as a substitute measure of disease risk in a given area.

It has been estimated by the World Health Organization that about 3 billion people worldwide use kerosene and solid-fuel fire or conventional stoves. People of poor socio-economic backgrounds must use solid fuels, since they are readily available at a cheaper cost in rural areas. According to the SDG7 Tracking report: Energy Progress Report 2018, 2.3 billion people will already use biomass worldwide if the present trend continues in 2030. Cooking energy is an important part of the overall 
consumption of household energy. Accessibility and the affordability of cooking fuel are becoming more problematic for vulnerable people every day at affordable rates. Many remain outside the electricity grid in modern times. Cooking fuels in rural areas of Pakistan, for example fuel-wood, crop residues and animal dung, are mainly unprocessed bio fuels. The use of these biofuels causes many difficulties, especially for women, which are adverse economic externalities (Barnes and Sen, 2000). Women play a very significant role in household operations (including animal care) in rural areas (Riasat et al., 2014).

Pakistan is primarily a rural society with nearly 70 per cent of the country's population, many of which depend on biomass fuel for their energy needs. Biomass fuel is a source of tremendous smoke when applied to conventional three stone stoves (created with clay and husk). The mean size of the household is calculated at 6.8 people. As 38 percent of households include one room with a kitchen, the concentrations of indoor air emissions are higher and the exposures are higher.

The Pakistan Household Energy Strategy study showed that 86 percent of overall household energy intake is accounted for by biomass fuels (Archar 1993). 94\% of the households in rural areas depend on biomass wood, and $58 \%$ in urban areas. Fuel is used to boil (82.1\%), heat water (9.8\%), and heat domestically (7.3\%) (Archar 1993).

Pakistan's health metrics are deceptive. While the health condition of the population has improved in the last 60 years, core medical indices remain behind other regional countries. The rate of maternal mortality decreased from 800 per 100,00o live births in 1978 to 350 currently registered and from 142 per 1,000 live births in 1970 to 74.6 in 2006, the mortality rate for infants declined. The rates of infant mortality in Pakistan are dominated by diarrheal diseases and acute respiratory (ARI) infections. In the last few decades, mortality from infectious conditions such as diarrhoea and vaccinepreventable diseases has fallen.

However, in other places such as ARI, there have been no changes (Nishtar 2007). A 2004 investigation showed that, in the previous two weeks of the survey (Multilateral Indicator Cluster Survesy of Pakistan, 2001-2004), 34 and 28 per cent of infants under five years produced ARI and diarrhoea. Indoor air quality accounted for 28,000 deaths per annum and 40 million acute respiratory illnesses according to the Pakistan Strategic Country Environmental Assessment (World Bank 2006).

Indoor air pollution in Pakistan is a considerable economic burden and costs 1\% of GDP annually. The literature presents the annual health effects predicted for annual cases and life years corrected for disabilities (DALYs). Because of indoor pollution, 82 percent is due to death and 18 percent to morbidity. DALYs are lost to up to $1,376,000$ annually.

Indoor air pollution is dependent on a range of factors, including energy technology in the house, such as the presence of a chimney and the mix of fuel storage, the housing environment, housing properties such as number of rooms and ventilation and behavioural determinants such as how long the house is spent (Ezzati and Kammen, 2001). In agricultural, developed, and developing and developed countries, major indoor contaminants differ, but they are a vector of diseases all over the world (Padilla et al., 2010).

Women and children can't avoid unhealthy exposure to biomass smoke in underdeveloped and developing countries. Women play a major role in the preparation and distribution of food to their families in the world's society (Bishokarma and Amir, 2014). Some young girls cook early at the age of 3-7 hours with their moms in their kitchen, to help their mothers prepare meals. 
Women are mostly affected by the health impacts of the household use of biomass fuel and coal. In women, the lack of physical and cultural access to health services also causes respiratory illnesses. Culturally, the education of women is a low priority, and female employment focuses on domestic tasks, most of which spend time inside a household. At present, there are few choices in developed countries for reducing indoor air pollutants (Saldiva and Miraglia, 2004).

During indoor activities, people may be subjected to pollutants from both indoor and outside sources that infiltrate the interior. The primary sources of air pollution indoors worldwide include burning of solid fuels, tobohemia, outdoor air contaminants as well as emissions from building materials and furniture (WHO 2006a). Overall, variations in the forms and capabilities of such origins are evident and closely related to socio-economic growth. The varieties, origins, concentrations and emission profiles of different indoor air contaminants are substantially different from the developing world in the developed world.

The explosion of the population and large-scale industrialization in developed countries and urbanisation also contributed to compact, low-air urban areas. In addition to poor air quality, the energy supply of biomass fuels will lead people in developed countries to high concentrations of indoor air pollution. More than three billion people worldwide, primarily in developed countries, rely on biomass fuel (wood, dung, and crop residues) for household energy (WHO 2007a).

The World Health Organization's most recent study on the national burden of indoor air pollution diseases $(2007 \mathrm{c})$ confirms the link between solid fuel indoor air pollution and a variety of diseases such as chronic and acute respiratory diseases, tuberculosis, cardiovascular disease, and prenatal health outcomes.

\section{Rationale of the Study}

Because of a lack of resources, Pakistan is in a critical state in terms of health. Health-related issues are increasing among women in rural areas of Punjab province, Pakistan. Energy crises and the government's lack of attention to rural areas in terms of providing facilities are common. Due to agricultural biomass and living in a polluted climate, the mortality rate is increasing among women in lower Punjab. In this scenario, modalities are insufficient for improving the lifestyle. Sufficient evidence from previous studies reveals that the use of agriculture biomass and indoor air pollution as risk factors for women's health that cause respiratory and non-respiratory diseases among women. As a result, research into the effects of agricultural biomass and indoor air pollution on women's health was required.

\section{Objectives of the Study}

1. To determine the socio-economic attributes of the respondents.

2. To identify the rate of use of biomass fuel.

3. To identify the risk factors associated with biomass and indoor air pollution.

4. To examine the hazardous effects of biomass emissions on women's health.

\section{Hypotheses}

1. There is a relationship between age and respiratory diseases among women.

2. There is a significant impact of the use of agricultural biomass on women's health.

3. There is a significant effect of the frequency of use of biomass on women's health.

4. There is a significant effect of exposure to smoke on women's health. 
5. The role of kitchen types and types of stoves is significant in relation to respiratory diseases among women. The sizeof the kitchen and time spent in the kitchen are the predictors of healthrelated complications among women.

6. There is a significant difference in the use of agricultural biomass, indoor air pollution, respiratory and non-respiratory diseases.

\section{Significance of the Study}

This research would explore latent aspects of biomass fuels and high emission air emissions contributing to excessive levels of indoor and local air pollution, mostly higher than international environmental air quality requirements in rural South Pakistan. This study will also help understand the association between types of biomass fuel, stove type, kitchen type, and health-related threats. Through this study, the medical community will know the risk factors for women's health due to biomass and indoor air pollution, such as breathing problems, coughing, and chest pain. The results of this research are a compelling argument for health policies and services aimed at reducing biomass fuel exposure to smoke. General exposure risk information campaigns are expected. In places where the changeover to renewable fuels is impossible due to financial considerations, an effective way to reduce its adverse impact is to improve the way biomass is provided and used for cooking. Furthermore, it will provide the incidence and prevalence of leading factors of health-related problems. Ultimately, it will disclose the level of awareness about biomass and indoor air pollution with its chronic effects on women's health.

\section{Methods}

Punjab is the most populated province of Pakistan, with an estimated population of 10,012,442, and it is the second-largest area (Census of Pakistan, 2017). There are three divisions and eleven districts in Southern Punjab. Empirically, it is investigating biomass fuel emissions and their implications for women's health in rural Punjab. South Punjab will be categorized in the current study using the purposive sampling technique. A survey method will be developed for data collection. The majority of the survey method's questions will be used to collect data. Most of the questions in the survey will be close-ended.

The sample of the study was comprised of 600 rural women who were selected from the three divisions of South Punjab, Pakistan. There are Eleven Districts and Twenty Two Tehsils in South Punjab. By using stratified random sampling, selected two rural union councils from each tehsil were approached. Household rural women were interviewed for this survey.

A multi-stage sampling technique was used for data collection. First of all, the cluster sampling technique was used to draw the area's categorization; Multan, Bahawalpur, and Dera Ghazi Khan. Secondly, the stratified sampling technique was employed to categorize the districts.

A research instrument was developed by the researcher to measure the variables; Agriculture Biomass, Indoor Air Pollution, Frequency of Uses, Exposure with Smoke, Kitchen Type, Types of Stoves, Kitchen Ventilation System, Kitchen Size and Time spent in Kitchen and Women's Health (Respiratory Diseases and Non-respiratory Diseases). This tool was divided into 10 dimensions with 72 items each. Responses were taken in closed-ended and open-ended format.

Data was analyzed through descriptive and as well as inferential statistics by using different statistics techniques; Pearson Product Moment Correlation Coefficient, Multiple Regression and Analysis of Variance (ANOVA) with SPSS. In the present study, the Pearson Correlation was used to 
examine the relation between the variables. Multiple regressions were used to assess the impact of risk factors on women's health, such as the use of agricultural biomass and indoor air pollution. The analysis of variance was used to compare the differences in the use of agricultural biomass, indoor air pollution, the level of respiratory diseases, and non-respiratory diseases in Multan, Bahawalpur, and Dera Ghazi Khan.

7. Results

Table: Demographic statistics

\begin{tabular}{|c|c|c|}
\hline Variables & $\mathbf{F}$ & Percentage \\
\hline \multicolumn{3}{|l|}{ Age } \\
\hline Up to 30 & 268 & $44.47 \%$ \\
\hline $31-40$ & 217 & $36.2 \%$ \\
\hline Above 40 & 115 & $19.2 \%$ \\
\hline \multicolumn{3}{|c|}{ Marital Status } \\
\hline Married & 389 & $64.8 \%$ \\
\hline Unmarried & 96 & $16.0 \%$ \\
\hline Widow & 81 & $13.5 \%$ \\
\hline Divorce & 34 & $5.7 \%$ \\
\hline \multicolumn{3}{|c|}{ Area } \\
\hline Multan & 200 & $33.3 \%$ \\
\hline Bahawalpur & 200 & $33 \cdot 3 \%$ \\
\hline Dera Ghazi Khan & 200 & $33.3 \%$ \\
\hline \multicolumn{3}{|c|}{ Income } \\
\hline Up to 20000 & 324 & $54.0 \%$ \\
\hline $20001-30000$ & 198 & $33.0 \%$ \\
\hline Above 30000 & 78 & $13.0 \%$ \\
\hline \multicolumn{3}{|c|}{ Education } \\
\hline Illiterate & 226 & $37.7 \%$ \\
\hline Primary & 155 & $25.8 \%$ \\
\hline Middle & 132 & $22.0 \%$ \\
\hline Matric or above & 87 & $14.5 \%$ \\
\hline
\end{tabular}

Table 1: Relationship between Age, Respiratory Diseases and Non-respiratory Diseases

\begin{tabular}{|l|l|l|l|l|l|}
\hline & Mean & Std.Deviation & $\mathbf{1}$ & $\mathbf{2}$ & $\mathbf{3}$ \\
\hline 1- Age & 1.7450 & .75780 & 1 & $.082^{*}$ & $.127^{* *}$ \\
\hline 2- Respiratory Diseases & 8.4800 & 1.57811 & & 1 & $.587^{* *}$ \\
\hline 3- Non-respiratory Diseases & 16.0450 & 2.50801 & & & 1 \\
\end{tabular}


Table 2: Standard Regression Model showing impact of Use of Agriculture Biomass, Indoor Air Pollution, Frequency of Uses, Exposure with Smoke, Kitchen Type, Types of Stoves, Kitchen Ventilation System, Kitchen Size and Time spend in Kitchen on Respiratory Diseases among Women

\begin{tabular}{|l|l|l|l|l|l|l|l|}
\hline Model & $\mathrm{B}$ & Std.Error & Beta & $\mathrm{t}$ & Sig. & $\begin{array}{l}\text { Lower } \\
\text { Bound }\end{array}$ & Upper Bound \\
\hline 1 (constant) & 6.044 & .666 & & 9.080 & .000 & 4.736 & 7.351 \\
UAB & .043 & .017 & .132 & 2.477 & .014 & .009 & .078 \\
IAP & -090 & .048 & -089 & -1.901 & .058 & -.184 & .003 \\
FU & -148 & .048 & -123 & -3.060 & .002 & -.243 & -.053 \\
EWS & -001 & .032 & -002 & -.045 & .964 & -.064 & .061 \\
KT & .415 & .094 & .227 & 4.389 & .000 & .229 & .600 \\
TS & -145 & .089 & -079 & -1.626 & .105 & -.321 & .030 \\
KVS & .160 & .041 & .226 & 3.934 & .000 & .080 & .239 \\
TSK & -207 & .093 & -084 & -2.231 & .026 & -.389 & -.025 \\
\hline
\end{tabular}

R2 $=0.213$, Adjusted R2 $=0.202,(F(1,599)=19.938, \mathrm{p}<0.05)$

Table 3: Standard Regression Model showing impact of Use of Agriculture Biomass, Indoor Air Pollution, Frequency of Uses, Exposure with Smoke, Kitchen Type, Types of Stoves, Kitchen Ventilation System, Kitchen Size and Time spend in Kitchen on Non-respiratory Diseases among Women

\begin{tabular}{|l|l|l|l|l|l|l|l|}
\hline Model & $\mathrm{B}$ & Std.Error & Beta & $\mathrm{t}$ & Sig. & $\begin{array}{l}\text { Lower } \\
\text { Bound }\end{array}$ & Upper Bound \\
\hline 1 (constant) & 6.868 & .941 & & 7.302 & .000 & 5.021 & 8.716 \\
UAB & .178 & .025 & .343 & 7.224 & .000 & .130 & .227 \\
IAP & .031 & .067 & .019 & .457 & .648 & -.101 & .163 \\
FU & -.131 & .068 & -.069 & -1.926 & .055 & -.266 & .003 \\
EWS & .058 & .045 & .049 & 1.287 & .199 & -.030 & .146 \\
KT & .497 & .133 & .171 & 3.721 & .000 & .235 & .759 \\
TS & .052 & .126 & .018 & .413 & .680 & -.196 & .300 \\
KVS & .158 & .057 & .141 & 2.756 & .006 & .045 & .271 \\
TSK & -.501 & .131 & -.128 & -3.818 & .000 & -.758 & -.243 \\
\hline
\end{tabular}

R2 $=0.377$, Adjusted R2 $=0.369,(F(1,599)=44.768, \mathrm{p}<0.05)$

\section{Discussion}

Pakistan is a developing and agricultural country; with rural areas housing the majority of the population (Pakistan Economic Survey, 2018-19).Pakistan is still dependent upon conventional resources for energy production. The purpose of this research is to look into the potential risk factors for women's health associated with agriculture biomass and indoor air pollution. Agriculture biomass is commonly used in areas where Sui gas is unavailable, and it has an impact on indoor air quality.

Agriculture biomass is commonly used in areas where Sui gas is unavailable, and it has an impact on indoor air quality. The current study was designed to investigate the impact of agricultural biomass on indoor air pollution. Descriptive research design with multistage sampling technique was used for this study. Respondents were 600 rural females and the questionnaire was used as a tool for 
data collection. Punjab is the most populated area with an estimation of 10,012,442 population (censes, 2017). The area of southern Punjab consists of 3 divisions, 11 districts and 22 Tehsils. The stratified sampling random technique was used to select two Tehsils. In addition, two rural union councils were chosen using the purposive sampling technique.

The results demonstrate there is a positive relationship between age, respiratory diseases and non-respiratory diseases. The strongest relation was reported between respiratory and non-respiratory as compared to age and non-respiratory diseases. Another significant study outcome is the significant impact of bio mass usage (UAB), indoor air pollution (IAP), frequency usage (FU), kitchen type (KT), kitchen ventilation system (KVS), and time spent in kitchen (TSK) on women respiratory diseases, whereas type of stove (ST) and exposure with smoke (EWS) have been found to have a non-significant impact on Respiratory Diseases among Women. Impact of above-mentioned variables predicts up to $20 \%$ of respiratory diseases in women. Furthermore, the results show the impact of agriculture biomass usage, indoor air pollution, usage frequency, smoke exposure, kitchen type, stove type, ventilation system in kitchens, kitchen size, time spent on non-respiratory diseases in women. The combined impact of independent variables is $36.9 \%$ on women's health. It explained that a sick mother due to poor indoor air, combined perhaps with other impacts of kitchen, stove and solid fuel use such as long hours in gathering fuel, has difficulty taking good care of her children and other family members and therefore increases the risk of disease.

These are the two common explanations for further use by the research community, close to the results of a study in Ethiopia and Kenya (Tamire, 2018). The associations of socio-demographic factors with exposure to biomass fuel were analyzed and it became clear that the use of biomass fuel in life was substantially linked to people who are over 45 , those with low levels of learning (o-5 school years), who work for unskilled or homemaker jobs, and women of a low socio-economic status. A growing tendency was identified in Malawi to use firewood at an increasing age, ranging from 33\% of women between the ages of $17-24$ and around $45 \%$ of women between four and five to $56 \%$ of women between sixty and eighty years of age, and low family income correlated with biomass fuel consumption, Washington: World Bank, Malawi (2018)

In rural areas, agriculture biomass is widely used. The largest group of respondents were with an age range of up to 30 years (268 respondents), followed by 31-40 years (217 respondents) and the least frequent age range in this study was above 40 (115 respondents). According to the findings, agriculture biomass is primarily used as fuel in Pakistan because it is abundant and does not require further processing to serve as fuel.

Indoor air pollution is highlighted in this study as a problem that affects the indoor quality of air. Inadequate humidity and poor air circulation and ventilation systems were reported as a problem that affects the indoor quality of air. These circumstances result in high indoor air contaminants that are harmful to health. Without proper ventilation, the indoor air quality becomes worse and breathing in worse air. The kitchen type is another important factor that contributes to low indoor air quality in the kitchen. Mostly, kitchens are blocked and small sized, with inadequate flow of air leaving polluted residuals inside the room/kitchen. The approximately average time spent in the kitchen was reported.

\section{Conclusion}

The current study aimed to look into the impact of agricultural biomass and indoor air pollution as a risk factor for women's health. Reported that there is a positive relationship between age, respiratory diseases and non-respiratory diseases. Results of the study indicate that all study variables 
(impact of agriculture biomass usage, indoor air pollution, usage frequency, smoke exposure, kitchen type, stove type, ventilation system in kitchens, kitchen size, time spent) on respiratory diseases in women have an impact of $20 \%$ on respiratory disease among women. The impact of the above mentioned variables is significant, which demonstrates that, collectively, these variables predict up to $36.9 \%$ of respiratory diseases in women. These were the two common reasons quoted by our study population for continuing its use. Fuel choice has adverse health impacts on women (Smith et al., 2017).

Indoor air pollution from poor fuel use greatly affects people's morbidity and mortality. Even though houses generally consume comparatively less fuel than industries, it is a greater source of danger as it is resilient and stays for a long time. Combining that with the large time duration for exposure, especially in children and women, makes this a prime threat to global diseases. This problem is greatly neglected by many people and it is not difficult to find solid connections between exposure to these gases and diseases in children and adults.

Biomass fuel creates a large amount of pollution, especially when combusted incompletely (e.g. $\mathrm{CO}, \mathrm{SO}_{2}$, particulate matter etc.). Due to this, the use of such fuels can have drastic impacts on human health by causing a number of diseases (like asthma, cancer, respiratory tract infections, cataract, chronic obstructive lung disease, tuberculosis, cardiovascular diseases). It also damages the neonatal outcome (infant mortality, low birth weight, preterm delivery etc.) A large amount of evidence suggests that IAP causes pneumonia in children five years or younger, while for people over 30, it can cause cancer and respiratory disorders. Much evidence also suggests a relation between IAP and poor births like low birth weight, cancers and heart diseases in the newborn.

\section{Policy Recommendations}

Pakistan is a developing country, so it requires cost-efficient ways of producing energy resources. Biomass is the most appropriate method to generate energy. The government is considering significant technological measures of energy production from biomass. In addition to this, access and use of modern cooking fuels should be increased. Strict rules for smoking. Public awareness should be prioritized. Studies should be conducted which not only deal with the effects but also the causes of indoor air pollution. Considering women's and children's health and comfort issues would result in numerous viable, ecological, and socioeconomic benefits. Women and children are at higher risk as they spend more time within homes or near stoves. The lack of good indoor air quality caused by the use of biomass fuel needs to be addressed, and steps that are acceptable and applicable to the local people should be taken in this regard.

1. Launching public awareness campaigns about the negative effects of fossil-fuel-based energy.

2. Identifying renewable energy sources and technologies.

3. Should make plans to reduce operational costs and meet the needs of the biomass industry.

4. Basic health units provide awareness and treatment to people with respiratory diseases due to poor air quality.

5. Different IAP intervention strategies should be developed as clean fuel supply, fuel efficiency, better stoves and better construction designs.

\section{Refrences}

Boschetto, P., Quintavalle, S., Miotto, D., Cascio, N. L., Zeni, E., \& Mapp, C. E. (2006). Chronic obstructive pulmonary disease (COPD) and occupational exposures. Journal of Occupational Medicine and Toxicology, 1(1), 1-6. 
Choi, J. Y., Baumgartner, J., Harnden, S., Alexander, B. H., Town, R. J., D'Souza, G., \& Ramachandran, G. (2015). Increased risk of respiratory illness associated with kerosene fuel use among women and children in urban Bangalore, India. Occupational and environmental medicine, 72(2), 114-122.

De la Sota, C., Lumbreras, J., Pérez, N., Ealo, M., Kane, M., Youm, I., \& Viana, M. (2018). Indoor air pollution from biomass cookstoves in rural Senegal. Energy for Sustainable Development, 43, 224-234.

Dutta, A., \& Ray, M. R. (2014). Hypertension and respiratory health in biomass smoke-exposed premenopausal Indian women. Air Quality, Atmosphere \& Health, 7(2), 229-238.

Fatmi, Z., Rahman, A., Kazi, A., Kadir, M. M., \& Sathiakumar, N. (2010). Situational analysis of household energy and biomass use and associated health burden of indoor air pollution and mitigation efforts in Pakistan. International journal of environmental research and public health, 7(7), 2940-2952.

GBD 2017 Risk Factor Collaborators. (2018). Global, regional, and national comparative risk assessment of 84 behavioural, environmental and occupational, and metabolic risks or clusters of risks for 195 countries and territories, 1990-2017: a systematic analysis for the Global Burden of Disease Study 2017. Lancet (London, England), 392(10159), 1923.

Household air pollution and health [Internet]. Geneva: World Health Organization; c2018 [cited 2018 Jun 1]. Available from: http://www.who.int/news-room/fact-sheets/detail/household-airpollution-andhealth

Indoor Air Pollution. Pollution [Internet]. Oxford: Our World In Data; c2018 [cited 2018 Jul o3]. Available from:https://ourworldindata.org/indoor-air-pollution

James, B. S., Shetty, R. S., Kamath, A., \& Shetty, A. (2020). Household cooking fuel use and its health effects among rural women in southern India-A cross-sectional study. PloS one, 15(4), e0231757.

James, B. S., Shetty, R. S., Kamath, A., \& Shetty, A. (2020). Household cooking fuel use and its health effects among rural women in southern India-A cross-sectional study. PloS one, 15(4), e0231757.

James, B. S., Shetty, R. S., Kamath, A., \& Shetty, A. (2020). Household cooking fuel use and its health effects among rural women in southern India-A cross-sectional study. PloS one, 15(4), e0231757.

Johnson, P., Balakrishnan, K., Ramaswamy, P., Ghosh, S., Sadhasivam, M., Abirami, O., ... \& Subhashini, A. S. (2011). Prevalence of chronic obstructive pulmonary disease in rural women of Tamilnadu: implications for refining disease burden assessments attributable to household biomass combustion. Global health action, 4(1), 7226.

Kim, K. H., Jahan, S. A., \& Kabir, E. (2011). A review of diseases associated with household air pollution due to the use of biomass fuels. Journal of hazardous materials, 192(2), 425-431.

Lahiri, T., Chowdhury, S., Roychoudhury, S., Siddique, S., Banerjee, M., Mukherjee, S., ... \& Ray, M. R. (2007). Health effects of chronic exposure to smoke from biomass fuel burning in rural areas. World Health Organization Bulletin.

Lakshmi, P. V. M., Virdi, N. K., Sharma, A., Tripathy, J. P., Smith, K. R., Bates, M. N., \& Kumar, R. (2013). Household air pollution and stillbirths in India: analysis of the DLHS-II National Survey. Environmental research, 121, 17-22.

Lam, N. L., Muhwezi, G., Isabirye, F., Harrison, K., Ruiz-Mercado, I., Amukoye, E., ... \& Bates, M. N. (2018). Exposure reductions associated with introduction of solar lamps to kerosene lamp-using households in Busia County, Kenya. Indoor Air, 28(2), 218-227.

Landrigan, P. J., Fuller, R., Acosta, N. J., Adeyi, O., Arnold, R., Baldé, A. B., ... \& Zhong, M. (2018). The Lancet Commission on pollution and health. The lancet, 391(10119), 462-512.

Nworie, I. (2017). The Economics of Electricity Market Reforms in Developing Countries: An African 
Experience and Lessons (Doctoral dissertation, University of Portsmouth).

Parikh, J. K., Sharma, A., Singh, C., \& Neelakantan, S. (2016). Providing clean cooking fuel in India: Challenges and solutions. International Institute for Sustainable Development.

Saha, A., Atul, A., Hira, S., Naskar, N. N., \& Lahiri, T. K. (2017). Association of adverse neonatal outcome with biomass fuel use. Environmental Disease, 2(2), 55.

Shi, H., Magaye, R., Castranova, V., \& Zhao, J. (2013). Titanium dioxide nanoparticles: a review of current toxicological data. Particle and fibre toxicology, 10(1), 1-33.

Sinha, B., Vibha, R. S., \& Chowdhury, R. (2015). Allergic rhinitis: a neglected disease-a community based assessment among adults in Delhi. Journal of postgraduate medicine, 61(3), 169.

Smith, K. R. (2000). National burden of disease in India from indoor air pollution. Proceedings of the National Academy of Sciences, 97(24), 13286-13293.

Suryanarayana, R., Chandrappa, M., Santhuram, A. N., Prathima, S., \& Sheela, S. R. (2017). Prospective study on prevalence of anemia of pregnant women and its outcome: A community based study. Journal of family medicine and primary care, 6(4), 739.

Tielsch, J. M., Katz, J., Thulasiraj, R. D., Coles, C. L., Sheeladevi, S., Yanik, E. L., \& Rahmathullah, L. (2009). Exposure to indoor biomass fuel and tobacco smoke and risk of adverse reproductive outcomes, mortality, respiratory morbidity and growth among newborn infants in south India. International journal of epidemiology, 38(5), 1351-1363.

Tipre, M., Wickremesinghe, R., Nandasena, S., Kasturiratne, A., Larson, R., Meleth, S., ... \& Sathiakumar, N. (2019). Prenatal exposure to particulate matter (PM2. 5) and low birth weight in a Sri Lankan birth cohort. bioRxiv, 461632.

Wylie, B. J., Coull, B. A., Hamer, D. H., Singh, M. P., Jack, D., Yeboah-Antwi, K., ... \& MacLeod, W. B. (2014). Impact of biomass fuels on pregnancy outcomes in central East India. Environmental Health, 13(1), 1-9.

Yip, F., Christensen, B., Sircar, K., Naeher, L., Bruce, N., Pennise, D., ... \& Kapil, V. (2017). Assessment of traditional and improved stove use on household air pollution and personal exposures in rural western Kenya. Environment international, 99, 185-191.

Is the world on track to deliver energy access for all? [Internet].Washington: World Bank; c2018 [cited 2018 Apr 27]. Available from:https://www.worldbank.org/en/news/feature/2018/05/18/sustainabledevelopment- goal7 energy-access-all.s 